\title{
Microstructural and Topographic Characterization of Concrete Protected by Acrylic Paint
}

\author{
Carmen Couto Ribeiro ${ }^{\mathrm{a} *}$, Joana Darc da Silva Pinto ${ }^{\mathrm{b}}$, G. Cristina Godoy $^{\mathrm{a}}$,
}

Vicente Tadeu Lopes Buono ${ }^{\mathrm{a}}$, Tadeu Starling

\author{
${ }^{a}$ Escola de Engenharia, Universidade Federal de Minas Gerais - UFMG, Av. Antônio Carlos, 6627, \\ Bloco 01, Pampulha, CEP 31270-901, Belo Horizonte, MG, Brasil \\ ${ }^{\mathrm{b}}$ Pontifícia Universidade Católica de Minas Gerais - PUC Minas, Av. Dom José Gaspar, 500, \\ Coração Eucarístico, CEP 30535-610, Belo Horizonte, MG, Brasil
}

Received: July 7, 2011; Revised: January 3, 2013

\begin{abstract}
Concrete structures must be designed and constructed so as to resist the conditions established in the project design and suffer no deterioration for many years. In highly aggressive environments, in addition to the minimum layer covering the framework, the concrete must receive a protective coating. In this work, the efficiency of acrylic paint as a protective coating, while the concrete was placed in an aggressive environment, was assessed utilizing a profilometric and microstructural characterization. The concrete was dosed using the ACI - American Concrete Institute method. The specimens were prepared with $370 \mathrm{~kg} . \mathrm{m}^{-3}$ of cement and the water-binder ratio of 0.50 corresponds to the value established in NBR6118 $18^{1}$ types for concrete subjected to highly aggressive environments. With the use of profilometry, 3D topographical images and surface roughness parameters were generated, which allowed for the identification of the degradation process and the minimization of the effect of this attack on concrete that had received surface protection. The topographic roughness parameters, as well as the images and chemical components identified using SEM/EDS, made it possible to identify the process of deterioration of the concrete under acid attack and to minimize such effect in the coated concrete. The methodology adopted demonstrates that the application of acrylic paint as a protective coating for concrete in an aggressive environment minimizes its surface degradation and increases its durability.
\end{abstract}

Keywords: acrylic paint, protective coating, profilometry, electron microscopy

\section{Introduction}

Concrete is a widely used material in civil construction and the proportions of its constituting elements must provide for the requirements with respect to its resistance, workability, impermeability and durability, which are fundamental properties of concrete. Resistance is usually a general indication of the quality of the concrete, since it is directly related to the structure of the hardened cement mixture ${ }^{2,3}$.

The characteristics of hardened concrete must be defined by the mechanical forces to which it will be subjected and by its durability ${ }^{4}$.

In recent decades innumerous structures compromised due to problems related to durability have been observed, which indicates an urgent need to expand research on construction materials and methods with a focus on concrete quality, on external attacks that may come to affect it and on surface protection coatings ${ }^{5}$

Concrete that is to be exposed to aggressive environments must comply with the limits established in the NBR6118/2007 ${ }^{1}$ Brazilian Norms. The durability

*e-mail: carmencouto@oi.com.br is directly linked to the concrete's compressive strength and to its impermeability. These characteristics may be obtained through the adequate consumption of cement, a low water-binder ratio and a workability that is adequate for the proposed utilization ${ }^{3,4,6}$.

Concrete deterioration is rarely the result of one isolated cause. Frequently, even though a concrete may be satisfactory, despite some unfavorable aspects, a single adverse supplementary factor may lead to its deterioration. Permeability is the main factor determining the vulnerability of concrete to external agents. Hence, for a concrete to be durable, it must have low porosity or be protected from aggressive agents.

In adverse exposure conditions, special conservation and protection measures are also required, such as the application of hydrofugant revetments and impermeable paints on the surface of the concrete ${ }^{1}$. Among impermeable paints, acrylic paint is increasingly being employed due to its ease of application and its adherence to concrete.

Recent advancements in the field of chemistry have resulted in the development of innumerous types of protections, which, allied with innovations in application 
methodologies, allow for a guaranteed durability through a reduction in water absorption and in the permeation of aggressive gases and salts, provided the proposed coatings are periodically inspected in order to verify whether there is a need for renewal and to provide for their continued functionality.

In highly aggressive environments, in addition to the minimum layer over the rebar, the concrete must receive additional protection so as to reduce its porosity, to seal the surface and elevate the resistance to weathering ${ }^{7}$.

Among the coatings developed, paints play an important role since, when applied, they adhere to the concrete surface, thus forming a continuous low-permeability film. The paints, in addition to offering the required protection against the main aggressive agents, must feature resistance to weathering and photodegradation, prevent the development of fungi and bacteria and be resistant to minor impacts and scratches. They must also present chemical stability in relation to the concrete, given the elevated alkalinity of the substrate ${ }^{5}$.

The basic protection mechanism for surface paints consists of a continuous and semiflexible film. These paint coatings require a homogeneous and smooth substrate, with voids no larger than $0.1 \mathrm{~mm}$ and must feature greater flexibility than that of the concrete, in order to withstand minor movements in the structure. Most of these paint coatings are able to seal existing cracks of up to $0.1 \mathrm{~mm}$, but are not absorbed by possible posterior cracks that may come to occur in the structure, since the film is broken when the structure undergoes cracking after the paint coating has been applied. In other countries, high elasticity systems which are able to absorb movement up to $5 \mathrm{~mm}$ are already available ${ }^{5}$.

Protective coatings are made of raw materials that will influence their final properties. In the case of acrylic coatings, it is a monocomponent paint in acrylic resin emulsion obtained from the polymerizing action of acrylic monomers, such as the methyl methacrylate and t-butyl acrylate. The methyl methacrylate is hard and brittle and t-butyl acrylate is soft and elastic. Their combination results in copolymers with intermediate properties which are suitable for paints. These were specifically developed to be used in surface coatings for concrete structures ${ }^{8}$.

Industrial acrylic paints are not saponifiable, do not develop a yellowish hue over time and are resistant to abrasion. They are also resistant to photodegradation and to aggressive environments and thus keep their characteristic glossiness. Generally speaking, acrylic paint is similar in quality to chlorate rubber, even though it is more resistant to acid and alkaline spatters 9 .

As a result of a general assessment of the coatings being adopted by civil engineers as a function of the aggressive agents, Almusallam et al. ${ }^{10}$ classified protective concrete coatings into acrylics, polymer emulsions, epoxy resins, polyurethanes and chlorinated rubbers.

In "Methodology for application of the topographical analysis to the study of surface processes" the development of a 3D topographic analysis methodology to be applied in the study of surface of materials is presented ${ }^{11}$.

The present work, in order to assess protective coatings, shows that a more detailed characterization of surface topography can be adopted with the utilization of several parameters added to the usual roughness measurement that are of fundamental importance to demonstrate the performance of acrylic surface coating types that minimize surface degradation of concrete and increase its durability.

\section{Material and Methods}

\subsection{Concrete dosages}

Different dosages were adopted using the ACI - American Concrete Institute method and varying the quantities of cement and water-cement ratios in the production of concretes with compressive strength between 30 to $40 \mathrm{MPa}$. In this study the concrete was made with $370 \mathrm{~kg}$ of CPII-E 32 cement, $865 \mathrm{~kg}$ of natural fine siliceous aggregate, $1040 \mathrm{~kg}$ of coarse aggregate, $160 \mathrm{~L}$ of water $3.7 \mathrm{~kg}$ of polifunctional plastifying admixture and a water-binder ratio of 0.50 , which corresponds to the value determined by NBR6118 for concretes subjected to highly aggressive environments.

The $10 \times 20 \mathrm{~cm}$ cylindrical specimens were molded and subjected to a compression test in accordance with the NBR-5738 $8^{12}$ and NBR-5739 $9^{13}$ norms. Following the smoothing of the surface, the specimens were protected with a glass pane to avoid water loss through evaporation, since this water is calculated and is necessary for hydrating the cement. The specimens were kept in the moist cure room until the date of the compression test.

This study considers the concrete with compressive strength of $39 \mathrm{MPa}$, as shown in Table 1, obtained in function of the dosage utilized and the careful mixing, compacting and curing processes carried out for 28 days in a moist cure room, so as to prevent early micro cracks in the concrete.

\subsection{Effectiveness of surface coatings subjected to sulfuric acid attack}

In order to assess the efficiency of the acrylic paint as a protective surface coating for concrete subjected to sulfuric acid attack. The assessment of the protection furnished by the acrylic paint was performed by comparing samples, with and without protection, immersed in the acid aggressive environment $\left(\mathrm{H}_{2} \mathrm{SO}_{4}-2.5 \%\right)$.

Table 1. Evolution of resistance to compressive strength as a function of age.

\begin{tabular}{ccccc}
\hline \multirow{2}{*}{ Mixture } & \multirow{2}{*}{$\begin{array}{c}\text { Cement consumption } \\
\left(\mathbf{k g} / \mathbf{m}^{-\mathbf{3}}\right)\end{array}$} & Superplastifier & $\begin{array}{c}\text { Water-binder } \\
\text { ratio }\end{array}$ & \multicolumn{2}{c}{ Compressive strength (MPa) } \\
\cline { 4 - 6 } & 370 & $1 \%$ & 0.50 & $\mathbf{7}$ days \\
2 & 370 & $1 \%$ & 0.50 & $28,0 \pm 0,8$ \\
\hline
\end{tabular}




\subsection{Loss of mass}

First the degradation of the concrete was assessed based on the loss of mass in concrete test bodies with and without acrylic protection, before and after the chemical attack.

\subsection{Characterization of surface topography and $M E V / E D S$}

The surface degradation of the concrete, following the acid attack, was assessed using 3D images, topographic roughness parameters and Scanning Electron Microscopy - SEM/EDS ${ }^{14,2}$.

The 3D images and the topographic roughness parameters were obtained using the profilometry technique with a Hommelwerke T4000 profilometer. A mobile TKY600 touch up kit was used and a $15 \times 15 \mathrm{~mm}$ area of the sample top surface was scanned. Thirty measurements with spacing of $517 \mu \mathrm{m}$ were performed.

The mobile touch up kit features a very thin needle that sweeps the surface of the material, while converting its vertical displacements into a two-dimensional graphic chart that represents a profile. A great number of profiles from the top surface were collected, moving the needle in a direction perpendicular to the scanning direction. The interpolation of these profiles generates a 3D image, called 3D profilometry. The topographic images and the roughness parameters were obtained utilizing the Turbo Roughness software and a Hommel Map Expert 3.0 (Mountains) profilometer.

In considering the several different possibilities for approaching the concrete surface, the data for generating the images and the roughness parameters were composed in the following stages:

- Generating a tridimensional profile with no filter from the innumerous bidimensional scans of the top of the specimen;

- Removing the mold with a second level polynomial in the tridimensional profile with no filter to optimize the calculation of the topographic parameters, by reducing the interference of possible waviness in the profile obtained; and

- Obtaining filter-free profile roughness parameters $-S_{a}$, $\mathrm{S}_{\mathrm{q}}, \mathrm{S}_{\mathrm{p}}, \mathrm{S}_{\mathrm{v}}, \mathrm{S}_{\mathrm{t}}$ and $\mathrm{S}_{\mathrm{z}}$.

The mean roughness parameter, $\mathrm{Sa}$, is obtained through the arithmetic mean of the absolute values for the average plane deviations (above and below) within the scanned area. This parameter corresponds to the extension of the two-dimensional $\mathrm{Ra}$, which is the most common profilometry parameter.

The Sq, scanned surface standard deviation, is obtained based on the amplitude deviations of the plane of minimal squares in a sample area, and is thus a direct extension of the two-dimensional $\mathrm{Rq}$ parameter and also allows for the evaluation of roughness.

$\mathrm{Sp}$ is the maximum height of the peaks in relation to the surface. Sv is the maximum depth of the valleys, also in relation to the surface.

$\mathrm{Sz}$, the height of ten surface points, is a parameter defined as the mean of the 5 highest peaks and the depth of the 5 lowest valleys within the same sampling area.

St is the height between the highest peak and the lowest valley.

Tests were conducted with a scanning electronic microscope (SEM), in order to analyze the microstructure of the concrete exposed to an aggressive environment, as well as the influence of the protective coating on durability.

The concrete has a very heterogeneous and complex structure, and has different constituents which are typically a cement paste, aggregate matter and a transition zone.

Samples that are electron-conductive, such as concrete, must be coated with a conductive material, in a process called metallization. For the analysis of the concrete surface, the metallization was performed using graphite. Therefore, the carbon visualized in the EDS (Energy-Dispersive Spectroscopy) spectra is a result of the metallization.

\section{Results and Discussion}

\subsection{Topographic characterization of surface texture of concrete}

Scans were performed on a $15 \times 15 \mathrm{~mm}$ area of the sample top surface, which was subdivided into 30 two-dimensional profiles generated by approximately 8,000 points each, which allowed for the topographic characterization of the concrete surface from a statistical point of view. Also worth noting is the fact that replicates were made in all the studied situations, which reaffirmed the same trend found for the analyzed deltas. Figures 1 and 2.

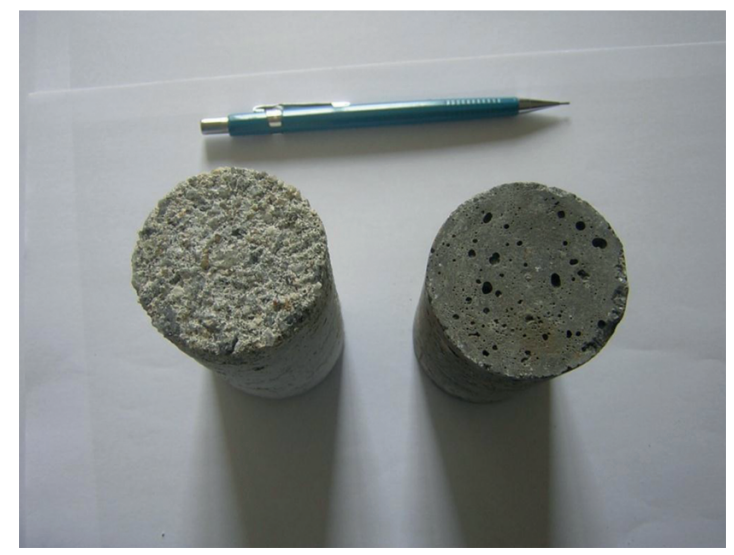

Figure 1. Specimens without protective coating, before and after $\mathrm{H}_{2} \mathrm{SO}_{4}$ attack.

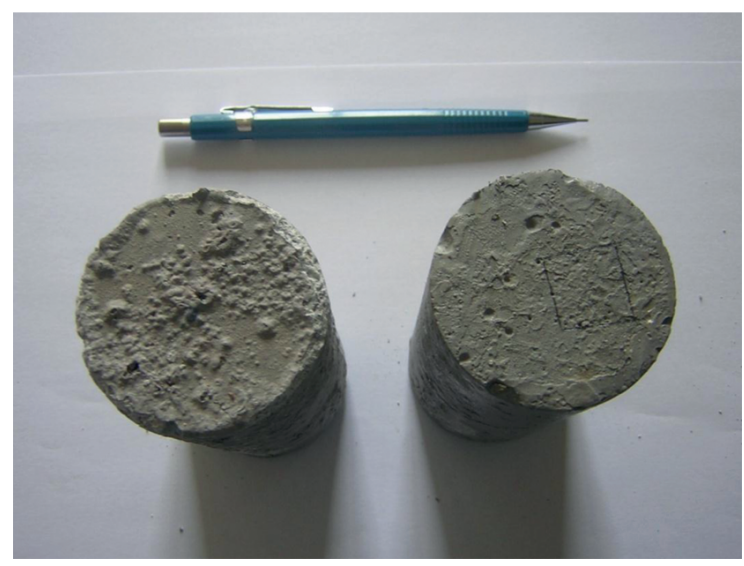

Figure 2. Specimens with acrylic paint protective coating, before and after $\mathrm{H}_{2} \mathrm{SO}_{4}$ attack. 
A clear degradation of the concrete with no protection was noted following the chemical attack in relation to its conditions prior to the attack (Figure 3), which may be confirmed through the parameter $S_{t}$, the distance between the highest peak and the deepest valley, which varied from $443 \mu \mathrm{m}$ to $1,429 \mu \mathrm{m}$, which corresponds to a variation of $223 \%$.

The performance of the acrylic paint, before and after the chemical attack, can be observed in the images (Figures 4), as can the variation of $215 \%$ in the $S_{t}$ parameter, from $398 \mu \mathrm{m}$ to $1.254 \mu \mathrm{m}$, which allows for the evaluation of the resulting effects of the chemical attack on the concrete with an acrylic paint protective coating.

The results obtained through the $\mathrm{S}_{\mathrm{t}}$ parameter (total surface height) suggest that other evaluations with respect to the degradation and the efficiency of the protection, utilizing the $S_{a}, S_{q}, S_{p}, S_{v}$, and $S_{z}$ parameters, should be performed. The efficiency of the protective coating of the concrete, compared with an unprotected concrete, may be confirmed through these roughness parameters, which are presented in Table 2.
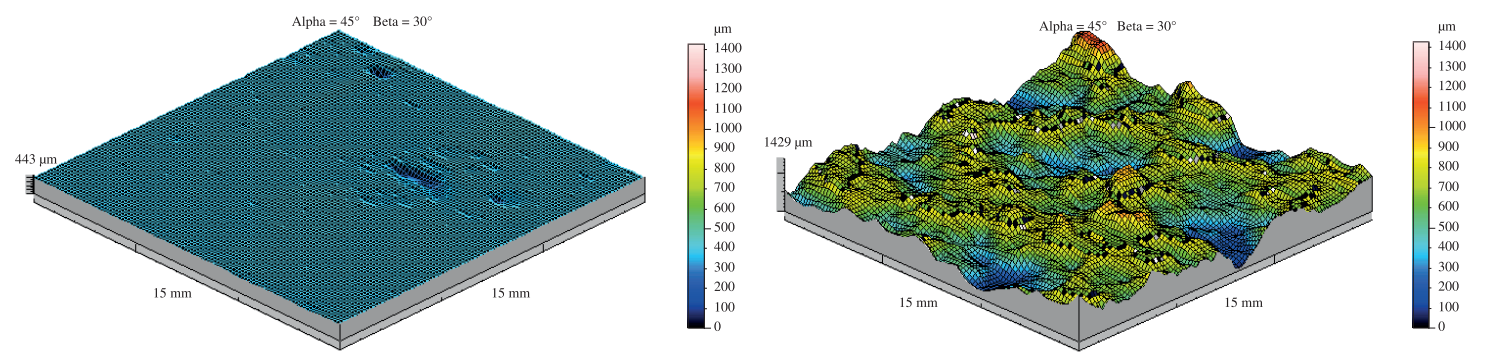

Figure 3. 3D Image of unprotected concrete, before and following chemical attack with $\mathrm{H} 2 \mathrm{SO} 4$.
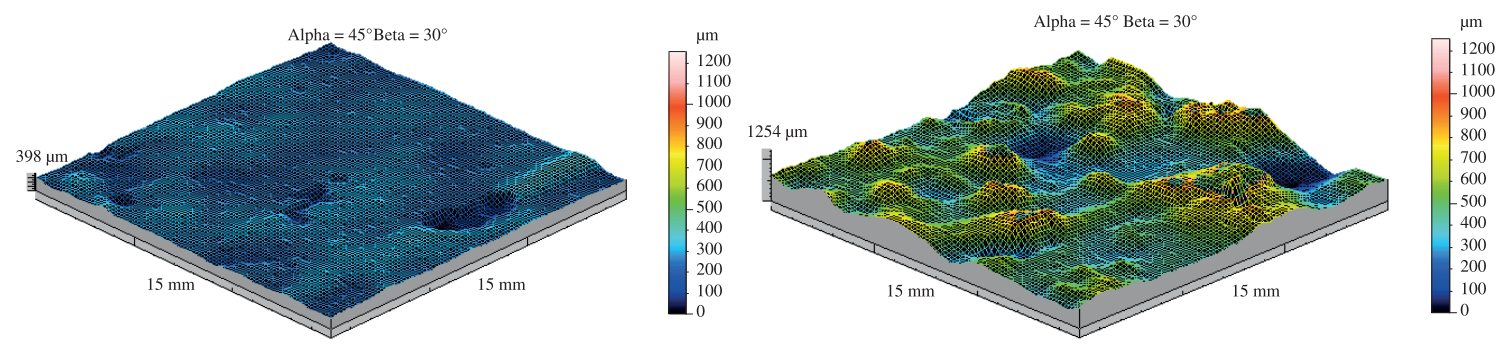

Figure 4. 3D image of concrete with acrylic protective coating, before and following the attack.

Table 2. Roughness parameters.

\begin{tabular}{|c|c|c|c|c|c|c|}
\hline \multirow[b]{2}{*}{ Parameters } & \multicolumn{3}{|c|}{ Concrete without protective coating } & \multicolumn{3}{|c|}{ Concrete with acrylic paint } \\
\hline & $\begin{array}{c}\text { Before the attack } \\
\qquad(\mu \mathrm{m})\end{array}$ & $\begin{array}{l}\text { Following the attack } \\
\qquad(\mu \mathrm{m})\end{array}$ & $\operatorname{Delta}^{*}(\%)$ & $\begin{array}{c}\text { Before the attack } \\
(\mu \mathrm{m})\end{array}$ & $\begin{array}{c}\text { Following the } \\
\text { attack }(\mu \mathrm{m})\end{array}$ & Delta* $(\%)$ \\
\hline $\mathrm{S}_{\mathrm{a}}$ & 7.62 & 157 & 1,960 & 24.4 & 125 & 412 \\
\hline $\mathrm{S}_{\mathrm{q}}$ & 15.8 & 202 & 1,178 & 37.8 & 164 & 334 \\
\hline $\mathrm{S}_{\mathrm{p}}$ & 47.8 & 740 & 1,448 & 121 & 739 & 511 \\
\hline $\mathrm{S}_{\mathrm{v}}$ & 395 & 689 & 74 & 277 & 515 & 86 \\
\hline $\mathrm{S}_{\mathrm{z}}$ & 239 & 1,129 & 372 & 297 & 965 & 225 \\
\hline $\mathrm{S}_{\mathrm{t}}$ & 443 & 1,429 & 223 & 398 & 1,254 & 215 \\
\hline
\end{tabular}

$*$ Delta $=\frac{\text { before the attack }- \text { following the attack }}{\text { before the attack }} \times 100$

Based on the comparison of the roughness parameters that measure the degree of degradation of the concrete under chemical attack, it is possible to observe a diminished variation in the $\mathrm{Sa}, \mathrm{Sq}, \mathrm{Sp}$ and $\mathrm{Sz}$ parameters for the concrete protected with the acrylic paint.

The Sa parameter, the arithmetic mean of the superficial roughness, increased from $7.62 \mu \mathrm{m}$ to $157 \mu \mathrm{m}$ following the attack on the concrete without coating and from $24.4 \mu \mathrm{m}$ to $125 \mu \mathrm{m}$ for the coated concrete. One can note that the variation in this parameter was $1.96 \%$ for the concrete without coating and $42.2 \%$ for the coated concrete, demonstrating the role played by the acrylic paint in diminishing the degree of concrete degradation.

The Sq parameter, which corresponds to the standard deviation of distribution, increased from $15.8 \mu \mathrm{m}$ to $202 \mu \mathrm{m}$, which means a variation of $1,178 \%$ for the concrete without a protective coating, while there was an increase from $37.8 \mu \mathrm{m}$ to $164 \mu \mathrm{m}$, meaning a variation of $334 \%$, for the coated concrete, a trend which was also found for the $\mathrm{Sa}$ parameter. 
Table 3. Losses in mass before and following the attack and parameters found in the perfilometry.

\begin{tabular}{|c|c|c|c|c|c|c|c|c|c|}
\hline \multirow[t]{2}{*}{ Concrete } & $\begin{array}{l}\text { Before the } \\
\text { attack }\end{array}$ & $\begin{array}{l}\text { Following } \\
\text { the attack }\end{array}$ & Delta* & $\begin{array}{l}\text { Before } \\
\text { the } \\
\text { attack }\end{array}$ & $\begin{array}{c}\text { Following } \\
\text { the } \\
\text { attack }\end{array}$ & Delta* & $\begin{array}{c}\text { Before the } \\
\text { attack }\end{array}$ & $\begin{array}{l}\text { Following } \\
\text { the attack }\end{array}$ & Delta* \\
\hline & \multicolumn{2}{|c|}{ Mass (g) } & $(\%)$ & \multicolumn{2}{|c|}{$\mathbf{S a}(\mu \mathbf{m})$} & $(\%)$ & \multicolumn{2}{|c|}{$\mathbf{S z}(\mu \mathbf{m})$} & $(\%)$ \\
\hline $\begin{array}{c}\text { Without } \\
\text { protective coating }\end{array}$ & $472.6 \pm 3.2$ & $463.7 \pm 3.2$ & 1.9 & 7.62 & 157 & 1,960 & 239 & 1.129 & 372 \\
\hline $\begin{array}{l}\text { With acrylic paint } \\
\text { coating }\end{array}$ & $481.3 \pm 3.0$ & $479.4 \pm 3.0$ & 0.4 & 24.4 & 125 & 412 & 297 & 965 & 225 \\
\hline
\end{tabular}

$*$ Delta $=\frac{\text { before the attack }- \text { following the attack }}{\text { before the attack }} \times 100$

The Sp parameter, which represents the maximum height of the peaks, increased from $47.8 \mu \mathrm{m}$ to $740 \mu \mathrm{m}$ following the attack, which corresponds to a variation of $1448 \%$ for the concrete without coating, and from $121 \mu \mathrm{m}$ to $739 \mu \mathrm{m}$, for a variation of $511 \%$, for the protected concrete.

The Sv parameter, which represents the deepest valley, did not feature a significant increase after the attack, increasing from $395 \mu \mathrm{m}$ to $689 \mu \mathrm{m}$, a variation of $74 \%$ for the unprotected concrete, and from $277 \mu \mathrm{m}$ to $515 \mu \mathrm{m}$, a variation of $86 \%$, for the coated concrete.

The $\mathrm{Sz}$ parameter, the mean of the 5 highest peaks and the depth of the 5 lowest valleys, also increased from $239 \mu \mathrm{m}$ to $1,129 \mu \mathrm{m}$, a variation of $372 \%$, for the unprotected concrete before and after the attack, and from $297 \mu \mathrm{m}$ to $965 \mu \mathrm{m}$ for the concrete with the acrylic coating, resulting in a variation of $225 \%$.

\subsection{Loss of mass}

Based on Table 3 it was possible to quantify the losses of mass in the concrete specimens subjected to chemical attack, as well as to correlate them with the corrosion of the material, through the roughness parameters Sa and Sz. The material that featured the largest loss of mass, of approximately $2 \%$, was the unprotected concrete, whereas the coated concrete underwent a $0.4 \%$ loss and the variations in the roughness parameters were $1,960 \mu \mathrm{m}$ and $412 \mu \mathrm{m}$ for the unprotected concrete and the coated concrete respectively, as confirmed by the variation in $\mathrm{Sz}$ in the different situations.

\subsection{Scanning Electron Microscopy-SEM}

The chemical components of the cement paste and of the aggregate matter were observed using the SEM/EDS. Among them were hydrated calcium silicates $(\mathrm{C}-\mathrm{S}-\mathrm{H})$, calcium hydroxide crystals (portlandite) and calcium sulfoalumminate, derived from the clinker obtained in the fabrication of cement. The chemical elements $\mathrm{Ca}$, resulting from $\mathrm{Ca}, \mathrm{Al}, \mathrm{Si}, \mathrm{O}, \mathrm{Mg}, \mathrm{Fe}$, originating from the quartz, feldspar, mica, amphibole and garnet, which are constituents of the crushed gneiss and natural sand, were also identified.

It is important to highlight that the volume of solids in a fully hydrated Portland cement paste is constituted of $50 \%$ to $60 \%$ hydrated calcium silicate, which makes it the most determining composite. In addition, portlandite constitutes between $20 \%$ and $25 \%$ of the hydrated cement paste volume and the calcium sulfoalumminates $\left(\mathrm{C}_{4} \mathrm{ASH}_{18}\right)$ represent from $15 \%$ to $20 \%$ of the volume of solids in the hardened cement paste.
Table 4. Chemical composition of concrete with and without protective coating - before and after chemical attack.

\begin{tabular}{ccccc}
\hline \multirow{2}{*}{ Elements } & \multicolumn{4}{c}{ wt. (\%) } \\
\cline { 2 - 5 } & \multicolumn{2}{c}{ Without coating } & \multicolumn{2}{c}{ With acrylic paint } \\
\cline { 2 - 5 } & Before & After & Before & After \\
\hline C & 30.0 & 37.9 & $\mathbf{6 3 . 0}$ & $\mathbf{4 8 . 7}$ \\
O & $\mathbf{2 3 . 5}$ & $\mathbf{2 3 . 8}$ & $\mathbf{1 3 . 1}$ & $\mathbf{2 1 . 8}$ \\
Na & 0.3 & - & 0.1 & 0.4 \\
Mg & 0.1 & - & 0.3 & 0.2 \\
Al & 0.7 & 0.4 & 1.5 & 3.8 \\
Si & 3.1 & $\mathbf{1 3 . 4}$ & 5.6 & $\mathbf{7 . 3}$ \\
S & 0.4 & $\mathbf{9 . 7}$ & 0.8 & 3.1 \\
Cl & - & - & 0.5 & 0.2 \\
K & 0.4 & 0.1 & 0.2 & 0.7 \\
Ca & $\mathbf{4 1 . 1}$ & $\mathbf{1 4 . 4}$ & 1.6 & 0.9 \\
Ti & - & - & $\mathbf{1 2 . 1}$ & $\mathbf{9 . 2}$ \\
Fe & 0.4 & 0.3 & 1.3 & 2.4 \\
Zn & - & - & - & 1.2 \\
\hline
\end{tabular}

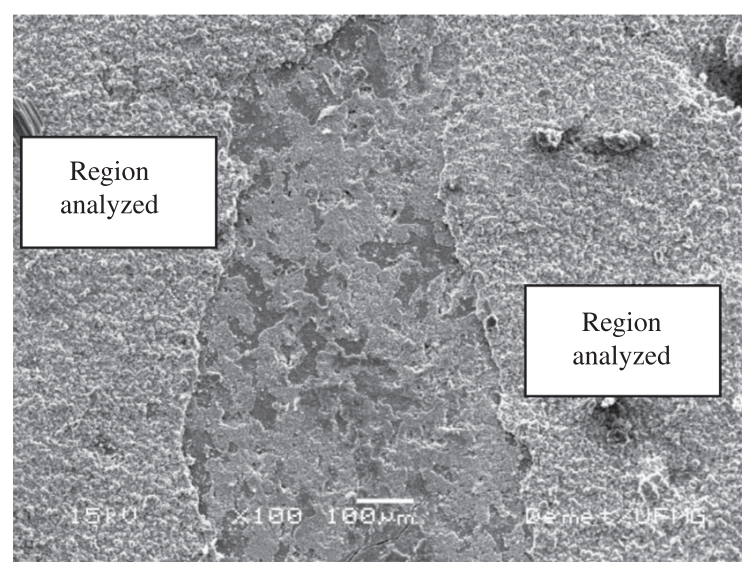

Figure 5. Secondary electron image, obtained using an electronic microscope (EM), of the concrete surface with no protection and not subjected to a chemical attack, amplified 100x.

Next, the images produced by the electronic microscope (EM) are presented along with the chemical composition of the surfaces of the concrete samples, before and following the chemical attack, both with and without protection, Table 4 and Figures 5 to 9. In Table 4, which shows the 


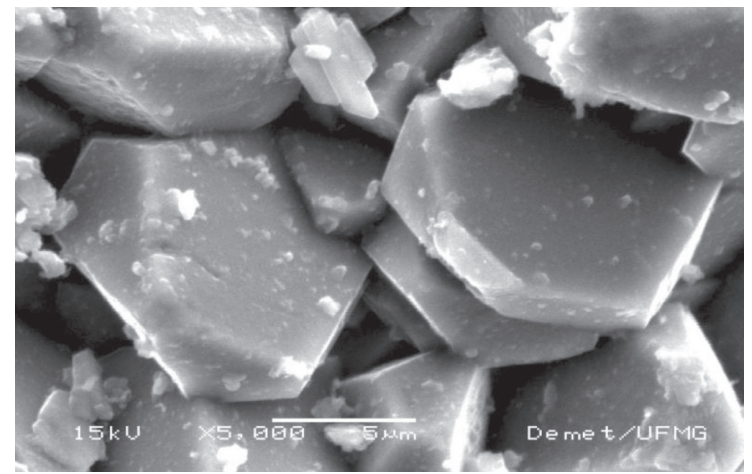

Figure 6. Image amplified 5,000× (Figure 5) of the concrete surface without protective coating and not under chemical attack, showing a detail of the portlandite crystals $\left[\mathrm{Ca}(\mathrm{OH})_{2}\right]$.

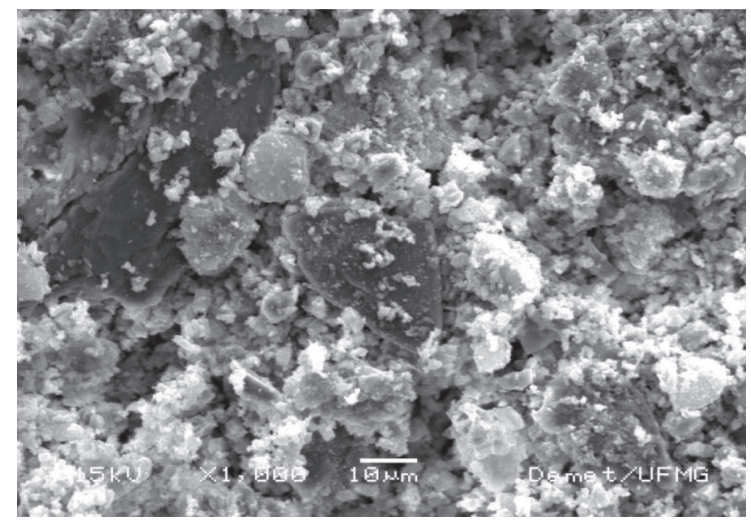

Figure 7. Image, amplified 1,000 times, of the concrete surface without protective coating and following chemical attack.

chemical composition of concrete without protective coating before chemical attack, note the predominance of $\mathrm{Ca}$ and $\mathrm{O}$ (41.0\% and $23.5 \%$, respectively), indicating the presence of portlandite crystals $\left[\mathrm{Ca}(\mathrm{OH})_{2}\right]$ resulting from the hydration of the cement. Also worth noting is the fact that the cement paste contains $\mathrm{Al}$ and $\mathrm{Si}$. In Figure 6 large crystals in the form of hexagonal prisms can be seen, formed by the portlandite $\left[\mathrm{Ca}(\mathrm{OH})_{2}\right]$ present in the cement paste.

Portlandite crystals can be seen in Figure 7 covered by a whitish material. Through Table 4 , which shows the chemical composition of the concrete without protective coating after chemical attack, it is possible to conclude that this material is composed of $\mathrm{Si}$, which varied from $3.1 \%$ to $13.4 \%$, Ca varying from $41.0 \%$ to $9.6 \%$ and $\mathrm{O}$ varying from $23.5 \%$ to $27.8 \%$, which originate from the aggregate matter and from the sulfuric acid $\left(\mathrm{H}_{2} \mathrm{SO}_{4}\right)$ used in the attack on the concrete.

Next, images and the chemical composition of the concrete surface with acrylic protection, before and after the chemical attack, are presented (Figures 8, 9 and Table 4).

The image (Figure 8) obtained with the SEM depict more homogeneous surfaces, with no flaws in the coating, indicating a good adherence of the paint to the substrate. The EDS analysis shows a predominance of $\mathrm{C}, \mathrm{O}$ and $\mathrm{Ti}$ originating from the protective acrylic coating (Table 4),

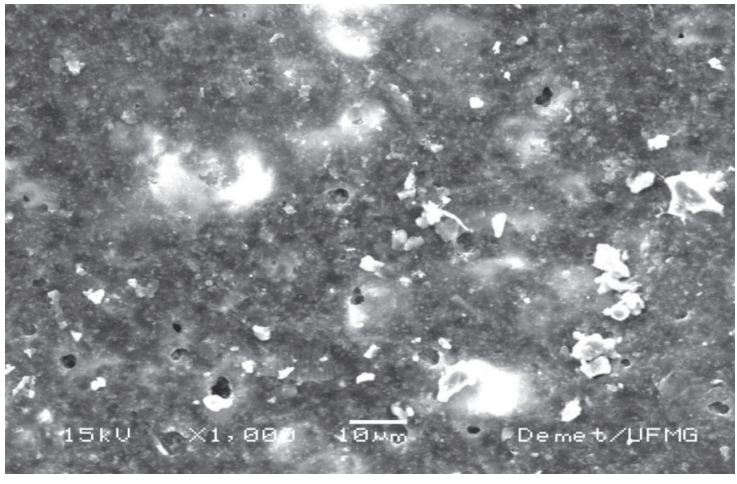

Figure 8. Image, amplified 1,000 times, of the concrete surface with the acrylic protective coating and without chemical attack.

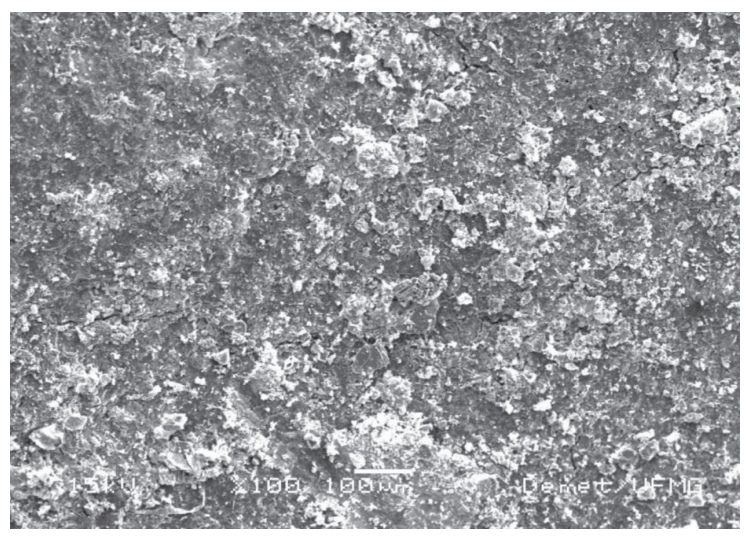

Figure 9. Image of the concrete surface with acrylic coating obtained following chemical attack, amplified 100x.

while the paint also contains $\mathrm{Al}, \mathrm{Si}$ and $\mathrm{Ca}$ in smaller proportions.

Figure 9 shows a whitish surface on the concrete protected with acrylic paint following attack with $\mathrm{H}_{2} \mathrm{SO}_{4}$, resulting from the sulfuric acid used during the attack. In the EDS a decrease in $\mathrm{C}$ may be observed, due to the degradation of the acrylic paint and an increase of $\mathrm{Si}$ and $\mathrm{O}$, as a consequence of the appearance of the concrete components.

\section{Conclusions}

The profilometric characterization, performed utilizing the topographic images of the Sa, Sq, Sp, Sv, St, and Sz roughness parameters allow for verification that the concrete subjected to an aggressive environment underwent surface degradation. Reductions in these parameters demonstrate the minimization of the concrete surface degradation with the utilization of the protective coating.

The efficiency of the acrylic coating may also be proven through the reduced losses in mass in the concrete specimens that underwent sulfuric acid attack. The minimization of the surface degradation of the concrete with the utilization of acrylic paint may be proven through the profilometric characterization.

The electronic scanning microscopy used on the unprotected concrete surface prior to the chemical attack 
allowed for the observation of a predominance of portlandite and of hydrated calcium silicate particulate matter originating from the cement paste, in addition to quartz and feldspar, originating from the aggregate. Following chemical attack, an increase in $\mathrm{Si}$ in those elements originating from the aggregate matter is observed, as they become more visible after the deterioration of the cement paste in the case of the unprotected concrete.

The efficiency of the acrylic paint as a protective coating may also be proven using SEM/EDS, since only a few points

\section{References}

1. Associação Brasileira de Normas Técnicas - ABNT. NBR6118: Projeto de estruturas de concreto. Rio de Janeiro: ABNT; 2007. $221 \mathrm{p}$.

2. Mehta PK. Concreto: Estrutura, Propriedades e Materiais. Editora Pini: São Paulo; 1994. 573 p.

3. Neville A. Propriedades do Concreto. 2. ed. Editora Pini: São Paulo; 1997. 828 p.

4. Ribeiro CC, Pinto JDS, Starling T. Materiais de Construção Civil. 3. ed. Editora UFMG: Belo Horizonte; 2011. 112 p.

5. Helene PRL. Manual para reparo, reforço e proteção de estruturas de concreto. 2. ed. São Paulo: Editora Pini Ltda; 1992. 213 p.

6. American Concrete Institute - ACI. Manual of concrete practice. ACI; 1973. part I.

7. Vipulanandan $\mathrm{C}$ and Liu J. Film model for coated cement concrete. Cemente \& Concrete Research. 2002; 32:1931-1936.

8. Gnecco C, Mariano R and Fernandes F. Tratamento de superficie e pintura. Rio de Janeiro: IBS/SBCA; 2003. 94 p. of protection had been damaged following the attack, in which materials that constitute the concrete were observed.

The results obtained allow for the identification of a degradation process in the concrete that was subjected to a chemical attack, as well as the mitigation of that effect with the application of the protective coating layer, thus demonstrating that the acrylic paint protection was found to be effective. It can therefore be concluded that the coating, while impeding the penetration of sulfuric acid, preserved the waterproofing condition that is fundamental for the durability of the concrete.

9. Nunes LP and Lobo AC. Pintura Industrial na proteção anticorrosiva. Rio de Janeiro: LTC - Livros Técnicos e Científicos Ed., Petrobrás; 1990.

10. Almusallam AA, Khan FM, Dulaijan SU and Al-Amoudi OSB. Effectiveness of surface coatings in improving concrete durability. Cement \& Concrete Composites. 2003; 25:473-481. http://dx.doi.org/10.1016/S0958-9465(02)00087-2

11. Unda AGR, Lin VFC and Godoy GCD. Metodologia para a aplicação da análise topográfica ao estudo de processos de superfície. Revista Matéria. 2007; 12(4):589-596.

12. Associação Brasileira de Normas Técnicas-ABNT. NBR5738: Moldagem e cura de corpos de prova cilíndricos ou prismáticos de concreto. Rio de Janeiro: ABNT; 2008. 9 p.

13. Associação Brasileira de Normas Técnicas-ABNT. NBR5739: Concreto - Ensaio de compressão de corpos de prova cilíndricos. Rio de Janeiro: ABNT; 2007. 4 p.

14. Mummery L. Surface texture analysis, The Hand Book. West Germany: Hommelwerke GmbH; 1992. 105 p. 